\title{
Développement in vitro de la lignée germinale foetale mâle chez le rat, la souris et l'homme
}

\author{
Gabriel LIVERA 1,2,3,4, Romain LAMBROT1,2,3,4, René FRYDMAN4,5 \\ Hervé COFFIGNY1,2,3,4, Catherine PAIRAULT 1,2,3,4, Béatrice PETRE-LAZAR1,2,3,4, \\ Stéphanie G. MORENO1,2,3,4, Virginie ROUILLER-FABRE1,2,3,4, René HABERT1,2,3,4
}

1 Univ. Paris 7 - Denis Diderot, Fontenay aux Roses ;

2 INSERM, U566, Unité de Gametogenèse and Génotoxicité, Fontenay aux Roses ;

3 CEA, DSV / DRR / SEGG / LDRG, Fontenay aux Roses ;

4 Institut Fédératif de Recherche 13, Clamart ;

5 Service de Gynécologie-Obstétrique de l'Hôpital Antoine Béclère, Clamart

Ce travail est dédié à la mémoire de José Maria Saez

\section{RESUME}

Le potentiel reproducteur de l'adulte dépend, en partie, de la mise en place de la lignée germinale pendant la vie fœtale et néonatale. Une hypothèse récente assez largement partagée suggère que l'augmentation des altérations de la reproduction masculine observée au cours des dernières décennies, comme la diminution de la production spermatique et l'augmentation de l'incidence des cancers testiculaires, résulterait de modifications du développement de la lignée germinale pendant la vie fœtale et néonatale en réponse à l'augmentation de la pollution environnementale. Cependant peu d'outils sont disponibles pour étudier le développement de la lignée germinale fœetale et néonatale.

Nous décrivons ici un système de culture organotypique dans lequel le testicule se développe sur un filtre flottant à la surface d'un milieu synthétique ne contenant ni sérum ni facteurs biologiques. Chez le rat et la souris, nous avons comparé le développement des cellules de Sertoli et des cellules germinales dans ce système avec leur développement observé in vivo. Ces cellules se développent normalement chez le rat sur une période de deux semaines. Moins de cellules sont produites qu'in vivo mais les fonctions de chaque cellule sont comparables. Des résultats similaires ont été observés chez la souris, mais la durée de maintien in vitro est plus courte que chez le rat et ce sont les stades fœtaux les plus jeunes qui donnent les meilleurs résultats.

En utilisant ce modèle, nous avons pu étudier le développement de la lignée germinale de testicules prélevés immédiatement avant la naissance sur des fœtus invalidés pour p63, un gène requis pour la survie postnatale, et montrer que p63 est impliqué dans le contrôle de l'apoptose néonatale de la lignée germinale. Enfin, nous avons étendu ce modèle de culture à l'espèce humaine ( 6 à 12 semaines de grossesse) et montré que l'on peut maintenir l'architecture testiculaire et les cellules germinales pendant 4 jours avec une efficacité supérieure pour les stades jeunes (moins de 8 semaines).

En conclusion, ce modèle est potentiellement très intéressant pour étudier l'effet de facteurs physiologiques ou toxiques sur la mise en place de la lignée germinale chez le mâle.

Mots clés : cellules germinales, foetus, culture, développement, testicule

Correspondance :

Pr René HABERT - Unité Mixte de Recherche sur la Gamétogenèse et la Génotoxicité. INSERM U566 ; CEA ; Université Paris 7 ; Equipe de Différenciation et Radiobiologie des Gonades ; CEA / DSV / DRR / SEGG / LDRG ; BP 6 - Route du Panorama ; 92265 Fontenay aux Roses, France - Tel 0146549499 - Fax 0146549906 Email rene.habert@cea.fr 


\section{INTRODUCTION}

Le développement de la lignée germinale mâle pendant la vie fœetale et néonatale jusqu'à la formation des spermatogonies présente une succession d'évènements bien caractérisés chez la souris et le rat $[2,48]$. Les cellules germinales primordiales (CGP) ont une origine ectodermique et se différencient dans la région proximale de l'épiblaste entre 6,5 et 7 jours post conception (jpc) chez la souris sous l'influence de facteurs produits dans cette région comme certains membres de la famille des Bone Morphogenic Proteins (BMP) [15]. Tout en se multipliant, les CGP migrent depuis ce territoire extraembryonnaire pour venir coloniser l'ébauche gonadique. À $7,5 \mathrm{jpc}$, les CGP sont retrouvées à la base de l'allantoïde dans l'endoderme définitif, puis, elles sont incorporées au cours des remaniements morphogénétiques dans l'endoderme intestinal. Elles migrent ensuite activement par mouvements amiboïdes via le mésentère dorsal vers les crêtes génitales qui se sont formées à la surface ventrale du mésonéphros. Les CGP atteignent les crêtes génitales à $11 \mathrm{jpc}$ chez la souris et à $12 \mathrm{jpc}$ chez le rat [48]. Les cellules germinales sont alors appelées gonocytes et la gonade montre le même aspect morphologique indifférencié chez le mâle et la femelle.

Alors que la gonade femelle conservera cet aspect indifférencié pendant plusieurs jours jusqu'à l'entrée en méiose, la gonade mâle s'organise précocement. En effet, à 12 jpc chez la souris et à 13,5 jpc chez le rat, les cellules de Sertoli se différencient, adhèrent les unes aux autres et englobent les cellules germinales pour former les cordons séminifères [31]. Les gonocytes montrent ensuite une chronologie de développement très particulière chez la souris et le rat. Les gonocytes prolifèrent jusqu'à $17,5 \mathrm{jpc}$ chez le rat [48] et $15,5 \mathrm{jpc}$ chez la souris [68] puis ils rentrent dans une période de quiescence et reprennent leurs mitoses à 1 jour post natal (jpp) chez la souris [45] et 2-3 jpp chez le rat [48]. Enfin, les gonocytes donnent naissance aux premières spermatogonies à 4 jpp chez la souris et à 6 jpp chez le rat $[6,12,45]$. II est à noter que les périodes de prolifération foetale et néonatale des gonocytes sont également des périodes d'apoptose de ces cellules [12].

Chez l'Homme, la chronologie de la mise en place de la lignée germinale mâle a également été étudiée. Les CGP commencent leur migration depuis la racine de l'allantoïde à 4 semaines de gestation et elles entrent dans la gonade au cours de la 5ème semaine [71]. Chez le mâle les cellules germinales sont ensuite englobées dans les cordons séminifères qui se différencient entre 6 et 7 semaines de grossesse [24,
71]. La caractérisation des cellules germinales fœtales a d'abord été réalisée par microscopie électronique et a montré plusieurs sous-populations [22, 27, 71]. Récemment, une étude immunohistologique utilisant des marqueurs des cellules germinales a permis de caractériser trois types de cellules germinales : les gonocytes, les cellules germinales intermédiaires et les préspermatogonies [23]. Cependant la connaissance de l'ontogenèse de la lignée germinale mâle humaine reste encore incomplète. En particulier, la numération des cellules germinales tout au cours de la vie intra-utérine n'a pas encore été réalisée. En outre, on ne sait toujours pas s'il existe ou non des périodes d'activités prolifératives et apoptotiques séparées par une période de quiescence à l'instar des rongeurs.

Pendant la vie fotale, le développement de la lignée germinale est indépendant des hormones hypophysaires $[43,46]$. Il est contrôlé par des régulations intratesticulaires qui jouent un rôle physiologique fondamental $[39,49,66]$ mais la connaissance de ces régulations reste encore très limitée.

Une meilleure connaissance du développement des cellules germinales foetales mâles est devenue récemment un objectif majeur de santé publique depuis que ces cellules sont supposées être la cible directe ou indirecte des toxiques environnementaux dont la diversité et la concentration dans l'environnement augmentent régulièrement $[3,16,18,61]$. Les principaux polluants chimiques incriminés sont les perturbateurs endocriniens à activité œstrogénique (xéno-œstrogènes) ou à effet anti-androgénique tels que les pesticides (insecticide, herbicides, fongicides), les agents plastifiants, les surfactants, et les phytoœstrogènes présents essentiellement dans l'alimentation et plus accessoirement dans l'atmosphère. L'hypothèse la plus couramment admise actuellement est i) que ces polluants seraient responsables de l'augmentation des altérations de la gamétogenèse observée au cours des dernières décennies telles que la baisse qualitative et quantitative de la production spermatique humaine [4, 65] et l'augmentation de l'incidence du cancer testiculaire [63], et ii) que ces polluants agiraient pendant la vie fœetale $[16,61]$. Cette hypothèse a été initialement formulée par Sharpe et Skakkebaek en 1993 [62] et de nombreuses observations effectuées sur la faune sauvage, ainsi que des analyses épidémiologiques, expérimentales et cliniques sont venues la conforter au cours des dernières années [18, 64, 70].

Les systèmes in vitro sont des outils précieux pour les études des régulations et des dérégulations du développement du testicule, mais l'interprétation des données peut être biaisée tant que l'on n'a pas démontré 
que la différenciation et le développement s'effectuent normalement dans de tels systèmes. Ainsi, en culture cellulaire, les gonocytes isolés montrent un très faible pourcentage de survie $[11,36,67]$ et il est possible que ceux qui survivent ne soient pas représentatifs de la totalité de la population. Le système de culture organotypique qui préserve l'architecture testiculaire et les communications intercellulaires nous est apparu comme un système plus approprié pour les études à long terme de la lignée germinale, une lignée particulièrement fragile in vitro.

Le système de culture organotypique de testicules fœetaux a déjà été utilisé chez le rat, la souris et l'homme. Chez le rat, les premières cultures ont été réalisées dans le laboratoire d'Alfred Jost dans les années 50 et 60 . Les testicules étaient alors déposés sur une grille enrobée d'agar. Ce système a été utilisé pour les études pionnières de l'AMH [30], de la production de testostérone $[26,53]$ et pour les études de la gamétogenèse du testicule néonatal $[10,59]$. Nos premières expériences en 1991 ont montré que l'activité stéroïdogène se développait moins bien lorsque le testicule était déposé sur une grille que lorsqu'il était déposé sur un filtre qui flotte à la surface du milieu [25].

Nous avions également observé que des plages de nécrose apparaissaient plus facilement sur grille que sur filtre, probablement en raison de la difficulté de maintenir le milieu à un niveau correct sur la grille dont la surface n'est jamais plane. Aussi, nous avons définitivement adopté le système de culture sur filtre flottant pour étudier les effets de différents facteurs sur la stérö̈dogenèse [34, 58], la gamétogenèse [49] ou les deux fonctions $[38,40]$ du testicule fœetal et néonatal du rat. Nous avons observé qu'au cours d'une culture de 2 ou 3 jours, les cellules de Leydig, de Sertoli et les gonocytes se développent de façon comparable au développement in vivo. Ces résultats ont été obtenus en utilisant un milieu de culture synthétique dépourvu d'hormone, de sérum et de tout facteur de signalisation. Ceci confère au modèle de culture une puissance supplémentaire dans l'interprétation des résultats car l'effet d'un facteur exogène ne résulte pas de son interférence avec d'éventuelles molécules de signalisation du milieu. Ce système de culture sur filtre flottant a alors été utilisé par d'autres équipes [14, 35]. Cependant, les cultures ne duraient pas plus de 3 jours et le présent article a été conduit pour analyser le développement de la lignée germinale chez le rat dans le système de culture organotypique sur une longue période.

Chez la souris, le système de culture organotypique des testicules fœtaux a été utilisé pour la première fois par Wolff [73]. Des cultures sur grille ont permis de mettre en évidence les effets des sécrétions du testicule sur le tractus génital en co-culture et d'étudier la production testiculaire de stéroïdes $[55,72]$. Plus récemment, des cultures sur blocs d'agar ont été utilisées pour étudier le lignage cellulaire et les événement cellulaires et morphologiques impliqués dans la différenciation testiculaire $[13,57]$. Cependant, le développement de la lignée germinale en culture organotypique n'a jamais été étudié chez la souris. En outre, toutes les précédentes études in vitro avaient été effectuées en présence de sérum. II restait donc à valider un système qui permette le développement de la lignée germinale mâle murine dans un milieu synthétique sans sérum. Un tel système est particulièrement important en regard des potentialités d'études génétiques de la souris.

Chez l'humain, deux études ont précédemment utilisé la culture organotypique pour analyser l'effet de différents facteurs sur le développement de la lignée germinale $[9,56]$. Cependant, elles n'ont pas validé le système car les auteurs n'ont pas quantifié le développement de la lignée germinale [9] ou bien ils ont seulement mesuré la densité de cellules germinales [56] alors qu'on sait que la structure du testicule foetal humain est très hétérogène [8]. La validation d'un système de culture organotypique de testicule foetal humain restait donc à faire. Ce système est particulièrement important en regard de la demande sociétale d'analyser les effets toxicologiques des polluants environnementaux.

Le but de l'étude présentée ici a donc été de caractériser et de préciser les limites du développement in vitro de la lignée germinale fœtale et néonatale mâle dans notre modèle de culture organotypique de testicule flottant sur un filtre dans un milieu synthétique dépourvu de sérum et de tout facteur de signalisation. Pour cela, nous avons comparé le développement des gonocytes dans notre système in vitro avec celui observé in vivo. L'étude a été conduite chez le rat, la souris et l'espèce humaine. Le présent article fait la synthèse de plusieurs de nos articles publiés ou sous presse et portant sur la technique de culture organotypique $[25,32,37,39,40,49,54]$.

\section{MATERIELS ET METHODES}

\section{Obtention des testicules fœtaux et néonataux de rongeurs}

Les rats Sprague-Dawley et les souris C57/BL6 ont été élevés sous des conditions standardisées de photopériode (lumière de 8 a.m. à 8 p.m.) et de température $\left(22-23^{\circ} \mathrm{C}\right)$. Ils ont été nourris par un régime commercial (U.A.R., Villemoisson sur Orge, France) avec de l'eau de boisson ad libitum. Les mâles étaient 
introduits dans les cages des femelles pendant la nuit. L'ovulation et la fécondation ayant lieu à 2 h00, le jour qui suit la nuit de l'accouplement est compté comme le jour 0,5 post conception $(0,5 \mathrm{jpc})$. La naissance a lieu entre $15.00 \mathrm{~h}$ à $21,5 \mathrm{jpc}$ et $18.00 \mathrm{~h}$ à $22,5 \mathrm{jpc}$ chez les rats et entre $18.00 \mathrm{~h}$ à $18,5 \mathrm{jpc}$ et $10.00 \mathrm{~h}$ à $19,5 \mathrm{jpc}$ chez les souris. Les jours 22,5 jpc (rat) et 19,5 jpc (souris) ont été comptés comme le jour 0 post partum ( $0 \mathrm{jpp}$ ).

Les animaux gestants ont été anesthésiés par injection i.p. de pentobarbital sodique (Sanofi, Libourne, France; $4 \mathrm{mg} / 100 \mathrm{~g}$ de poids corporel) et les fœtus ont été extériorisés après laparotomie. Les testicules fœataux ont été prélevés aseptiquement sous stéréomicroscope. $A$ 13,5 jpc chez le rat et à 11,5 jpc chez la souris, les gonades sont encore morphologiquement identiques dans les deux sexes. Nous avons donc déterminé le sexe du fœtus à ces âges par la recherche de la chromatine sexuelle sur la membrane amniotique pour le rat $[29,49]$ et par la recherche par PCR de SRY pour la souris (F,5'GTCAAGCGCCCCATGAATGCAT3' et $R$, 5'AGTTTGGGTATTTCTCTCTGTG3'). A ces stades, nous avons prélevé en une seule pièce les deux gonades et leur mésonéphros associé car toutes ces structures sont encore étroitement associées et il reste des cellules germinales dans le mésonéphros n'ayant pas encore colonisé la gonade. A partir de 14,5 jpc (rat) ou 12,5 jpc (souris), les testicules se distinguent des ovaires par leur aspect plus arrondi et par la présence de l'artère testiculaire qui court à la surface de l'organe. A ces âges, les testicules ont été prélevés dépourvus du tissu adjacent.

Le sexe des rats et des souris nouveau-nés a été identifié par la distance ano-génitale. Les testicules des nouveaux-nés mâles ont été prélevés immédiatement après sacrifice par décapitation.

\section{Obtention des testicules foetaux humains}

Les testicules foetaux humains provenaient d'Interruption Volontaire de Grossesse (IVG) réalisées entre 6 et 12 semaines de grossesse par le Service de Gynécologie et Obstétrique de l'Hôpital Antoine Béclère avec l'accord du Comité d'Ethique de l'hôpital. Les IVG ont été pratiquées par aspiration, $48 \mathrm{~h}$ après l'absorption par voie orale de $200 \mathrm{mg}$ de mifegyne (RU 486, RousselUclaf, France). Aucune IVG n'a été pratiquée pour raison médicale et tous les foetus apparaissaient morphologiquement normaux. Les fœetus ont été disséqués sous stéréomicroscope selon les règles d'Hygiène et Sécurité (Laboratoire L2) et les testicules ont été prélevés et immédiatement explantés in vitro ou bien immergés dans le fixateur. Le sexe du fœetus a été déterminé par la morphologie de la gonade. L'âge du fœtus a été évalué par la mesure de la longueur des membres et du pied [21]. Le pourcentage de testicule intact dans les produits d'aspiration est faible $(12 \%)$.

\section{Produits utilisés}

Le milieu de culture était le Ham's F12/Dulbecco's Modified Eagle's Medium (1:1) (Gibco, Grand Island, NY) additionné de 0,35\% glutamine (Flow Laboratories, Irvine, UK) et de $80 \mu \mathrm{g} / \mathrm{ml}$ de gentamicine (Gentalline, Schering-Plough, Levallois-Perret, France). Aucun sérum, hormone, facteur de croissance ou autre molécule de signalisation bioactive n'était ajouté au milieu. L'Hormone Lutéinisante ovine (oLH; NIH.LH S19; 1.01 NIH.LH.S1 unités/mg) était un don du Dr. A.F. Parlow (NIDDK, Bethesda, MD, U.S.A. et la hFSH recombinante $(12000 \mathrm{lU} / \mathrm{mg})$ un don du Dr. B. Mannaerts (Organon International, Pays Bas) [42].

L'anticorps anti-AMPc a été offert par le Dr J.M. Saez (INSERM U 369, Lyon, France). L'anticorps dirigé contre l'hormone anti-Müllérienne (AMH) de rongeurs provient de Santa-Cruz (CA, USA), l'anticorps anti-AMH humaine a été offert par le Dr. N. di Clemente (INSERM U 782, Clamart, France), l'anticorps anti 5-bromo-2'deoxyuridine (BrdU) provient d'Amersham (Buckinghamshire, Angleterre) et l'anti-Ki67 est un anticorps monoclonal de DAKO (Trappes, France). L'anticorps dirigé contre l'antigène nucléaire 1 des cellules germinales (GCNA1) a été offert par G. Enders [20]. Enfin l'anticorps anti-caspase 3 clivée a été fourni par Cell Signaling Technology (Beverly, MA).

\section{Culture organotypique et incubation ex vivo}

Les explants testiculaires ont été cultivés ou incubés sur filtres selon une procédure initialement publiée en 1991 [25] et légèrement modifiée depuis.

Pour les testicules issus de fœtus de rongeurs relativement âgés, nous avons obtenu une oxygénation correcte en coupant le testicule avant de le mettre en culture en deux (rat à 16,5 jpc et souris à 14,5 et 15,5 jpc), quatre (rat à $18,5 \mathrm{jpc}$ et souris à $17,5 \mathrm{jpc}$ ), huit (rat à 20,5 jpc et souris à $2 \mathrm{jpp}$ ) ou seize (rat à $3 \mathrm{jpp}$ ) morceaux. De même, les testicules fœtaux humains ont été coupés en $2,8,12$ et 16 morceaux à $6-7,8-9$, 10 et $11-12$ semaines de gestation respectivement avant d'être déposés sur le filtre.

Les deux testicules et leur mésonéphros (rat à 13,5 jpc et souris à $11,5 \mathrm{jpc}$ ), le testicule isolé entier (rat à 14,5 et $15,5 \mathrm{jpc}$ et souris à 12,5 et $13,5 \mathrm{jpc}$ ) ou tous les morceaux issus d'un même testicule (rat et souris à tous les autres âges, homme à tous les âges) ont été placés sur un même filtre. Ce filtre est individualisé (Millipore, HA, pore de 0,45 $\mu \mathrm{m}$, Bedford, MA, USA) pour les rongeurs ou inclus dans un insert (Millicell, filtre $\mathrm{CM}$ avec des pores de 0,4 $\mu \mathrm{m}$, Fisher Scientific 
Labosi, Elancourt, France) pour l'homme. Les filtres portant le ou les explants ont été mis à flotter sur 0,3 (homme) 0,4 (stades jeunes des rongeurs) ou 1,5 (stades tardifs des rongeurs) $\mathrm{ml}$ de milieu. Les cultures ont été réalisées à $37^{\circ} \mathrm{C}$ dans une atmosphère saturée en vapeur d'eau contenant $95 \%$ d'air et $5 \%$ de $\mathrm{CO}_{2}$.

Les testicules ont été incubés pendant 3 heures (ex vivo) ou cultivés pendant 3 à 21 jours avec changement du milieu tous les jours (in vitro). Dans certains cas, le milieu de culture a été conservé à $-20^{\circ} \mathrm{C}$ en vue d'un dosage d'AMPc ou de transferrine. Les testicules cultivés ou fraîchement prélevés ont été fixés pendant 2 à $24 \mathrm{~h}$ dans le liquide de Bouin, inclus dans la paraffine et coupés au microtome à $5 \mu \mathrm{m}$ d'épaisseur pour les analyses cellulaires. Pour les cultures à long terme (supérieures à 7 jours), des précautions spéciales ont été prises pour préserver la flottabilité des filtres. Aucune figure de nécrose n'a été observée quelle que soit la durée de la culture à condition d'éliminer les testicules dont le filtre support a coulé.

\section{Identification et comptage des cellules germinales}

Le principe a été publié en 1998 [49]. Les coupes sériées issues de la totalité d'un testicule ont été montées sur lames, déparaffinées, réhydratées et colorées à l'hématoxyline-éosine ou par la coloration de Tushmann. Selon les cas, les gonocytes ont été identifiés simplement sur la base de leur aspect morphologique (cellules sphériques avec une membrane plasmique clairement visible, un gros noyau sphérique légèrement coloré contenant des petits granules de chromatines et au moins deux nucléoles), ou bien après marquage positif de GCNA1, ou bien en tant que cellules non marquées dans les cordons séminifères après révélation immunohistologique de l'AMH.

La numération des gonocytes a été réalisée de la façon suivante. Tous les gonocytes d'une coupe sur 3 (rat de 13,5 à $15,5 \mathrm{jpc}$ et souris de 11,5 à $13,5 \mathrm{jpc}$ ), d'une coupe sur 10 (rat de 16,5 jpc à 3 jpp, souris de 14,5 jpc à 2 jpp et homme à 6-7 semaines) ou d'une coupe sur 20 (homme après 7 semaines) ont été comptés. Le nombre cumulatif obtenu a été multiplié par 3,10 ou 20 pour obtenir le nombre brut (NB) de gonocytes par testicule. Nous avons ensuite appliqué la formule d'Abercombrie pour tenir compte de la surestimation due au comptage en double d'une même cellule dans deux coupe successives : NR=NBxS/(S+D) où NR est le nombre réel, $S$ l'épaisseur de la coupe $(5 \mu \mathrm{m})$ et $D$ le diamètre moyen du noyau des gonocytes [1]. D s'obtient en divisant par $\pi / 4$ la moyenne des diamètres mesurés sur la coupe. Toutes les mesures et comptages ont été fait en aveugle en utilisant le système d'analyse d'images Histolab (Microvision Instruments, Evry, France).

\section{Marquage immunohistochimique de l'AMH}

La procédure est celle décrite par Vigier et al. en 1983 [69]. Après déparaffinage et réhydratation, les peroxydases endogènes et les liaisons protéiques non spécifiques ont été bloquées par une incubation avec $\mathrm{H}_{2} \mathrm{O}_{2}$ puis du sérum normal de chèvre. Après incubation avec l'anticorps anti-AMH, celui-ci a été révélé par une incubation avec de l'anticorps biotinylé de chèvre antilapin et le complexe avidine-biotine-péroxidase (Vectastain Elite ABC kit, Vector Laboratories, Burlingame, CA) en présence de 3,3'-diaminobenzidine (DAB).

\section{Révélation immunohistologique de GCNA1}

Le protocole a été celui décrit par Enders et al. [20]. Après déparaffinage et réhydratation, les coupes ont été incubées dans $0,3 \% \mathrm{H}_{2} \mathrm{O}_{2}$ pendant $15 \mathrm{~min}$ puis en présence d'anticorps anti-GCNA1 (don de G . Enders) pendant la nuit à $4^{\circ} \mathrm{C}$. Les coupes ont été ensuite incubées pendant $30 \mathrm{~min}$. à la température ambiante avec de l'anticorps anti-lgG de rat puis avec le complexe avidine-biotine-péroxidase en présence de DAB.

\section{Mesure de l'incorporation de BrdU}

Nous avons utilisé un kit immunohistochimique de mesure de la prolifération cellulaire (Amersham, Buckinghamshire, UK) pour mettre en évidence l'incorporation de BrdU pendant la phase $S$ dans les cellules en mitose selon la méthode initialement décrite en 1998 [49]. Le BrdU (1\%) a été ajouté au milieu de culture du testicule ex vivo ou in vitro pendant 3 heures. Au moins 3 coupes prises dans différentes parties du testicule (1er tiers, milieu et 2 ème tiers) ont été montées et incubées avec $0,3 \%$ d' $\mathrm{H}_{2} \mathrm{O}_{2}$ à $20^{\circ} \mathrm{C}$ pendant 30 min. dans le méthanol pour inactiver les peroxydases endogènes, puis avec un anticorps monoclonal de souris dirigé contre le $\mathrm{BrdU}$ à $20^{\circ} \mathrm{C}$ pendant 1 heure. L'anticorps fixé au noyau a été ensuite lié avec un anticorps antiIgG de souris couplé à la peroxidase et la peroxidase est visualisée en utilisant la DAB comme substrat. L'index d'incorporation du BrdU est le pourcentage de cellules montrant une immunoréactivité positive au BrdU obtenu par le comptage d'au moins 200 cellules.

\section{Révélation immunohistochimique de Ki67}

Ki67, un antigène nucléaire présent seulement chez les cellules cyclantes [60] a été utilisé comme marqueur de la prolifération des cellules germinales humaines. Les coupes montées sur lames ont été chauffées au microondes dans une solution perméabilisante $(0,01 \mathrm{M}$ d'acétate de sodium; $\mathrm{pH}$ 2) pendant $30 \mathrm{~min}$. Le protocole a ensuite été le même que pour la détection de l'AMH excepté que du sérum normal de cheval et de l'anticorps 
biotinylé secondaire de cheval dirigé contre les $\lg G$ de souris ont été utilisés.

\section{Révélation immunohistochimique de la caspase 3 clivée}

La caspase 3 est impliquée dans la plupart des voies apoptotiques [50]. Aussi, nous l'avons utilisé comme marqueur de l'apoptose. Les coupes montées sur lames ont été chauffées au micro-ondes dans une solution perméabilisante $(0,05 \mathrm{M}$ Tris ; $\mathrm{pH} 10,6)$ pendant 30 min. Le protocole utilisé a ensuite été le même que pour la révélation de l'AMH.

\section{Dosage de la sécrétion d'Adénosine 5'- monophosphate (AMPc)}

La sécrétion d'AMPc a été mesurée ex vivo ou après $72 \mathrm{~h}$ de culture en incubant les testicules pendant $3 \mathrm{~h}$ dans du milieu contenant $1 \mathrm{mM}$ de 3-isobutyl-1methylxanthine (IBMX) (Sigma, St Louis, MO, USA), en présence ou en absence de $200 \mathrm{mJU} / \mathrm{ml}$ d'hFSH recombinante [40]. Les milieux ont été acétylés et utilisés pour le dosage radioimmunologique de l'AMPc selon la méthode décrite par Bégeot et al. [7].

\section{Dosage de la sécrétion de transferrine}

La technique utilisée a été celle décrite par Le Magueresse et al. [33]. La transferrine standard provenait de SIGMA. La gamme étalon s'étendait de 0,2 à 200 ng/tube. Le coefficient intradosage de variation était de $8 \%$.

\section{Analyses statistiques}

Les valeurs présentées sont les moyennes \pm l'erreur standard à la moyenne (SEM). La signification statistique de la différence entre deux moyennes a été évaluée en utilisant le test $t$ de Student. Si la comparaison portait sur les 2 testicules d'un même fœtus nous avons utilisé le test de Student en valeurs appariées.

\section{RESULTATS}

\section{Comparaison du développement in vivo et in vitro des cordons séminifères}

\section{a) Rat}

In vivo, les cellules de Sertoli s'agrègent et entourent les gonocytes pour former les cordons séminifères entre 13,5 et 14,5 jpc [41]. Nous avons observé que cette morphogenèse se produit également in vitro avec des testicules fœtaux explantés à 13,5 jpc (Figure $1 \mathrm{~A}$ et B). En accord avec les données bibliographiques [52], nous avons observé que l'activité mitotique, évaluée par le pourcentage de cellules de Sertoli BrdU-positives ex vivo, augmente pendant la vie fœtale pour atteindre un maximum à 21,5 jpc. En culture organotypique, l'activité mitotique des cellules de Sertoli a été maintenue (Tableau 1). Le nombre de cellules de Sertoli qui se forment in vitro est plus faible qu'in vivo : 58000 et 672000 in vivo aux jours 18,5 et 21,5 pc, respectivement [42] vs 125000 dans le testicule de 18,5 jpc testé après 3 jours de culture. Dans le testicule de 18,5 jpc cultivé, aucune trace d'apoptose n'a été détectée par la méthode TUNEL dans les cellules de Sertoli. Nous avons observé qu'après la naissance, le pourcentage de cellules de Sertoli BrdU-positives diminue in vivo et in vitro : en utilisant des testicules de 3 jpp ce pourcentage est de $17,1 \pm 1,2 \%$ ex vivo et de $12,7 \pm 0,4 \%$ après 3 jours de culture.

Nous avons évalué l'activité fonctionnelle des cellules de Sertoli en mesurant la production d'AMPc en réponse à la stimulation aiguë par la FSH puisque les cellules de Sertoli sont les seules cellules testiculaires capables de répondre à la FSH (Tableau 1). Nous avons observé que l'AMPc produit en réponse à la $\mathrm{FSH}$ ex vivo augmente progressivement en fonction de l'âge fœtal. La capacité de répondre à la FSH augmente également in vitro, mais le niveau atteint après 3 jours de culture est plus faible que celui observé à l'âge correspondant in vivo. Nous avons également évalué la production de transferrine, un marqueur spécifique des cellules de Sertoli. La production ex vivo augmente avec l'âge [43] et augmente également au cours de la culture en conditions basales $(2,4 \pm 0,7,3,3 \pm 0,4$ et $6,1 \pm 1,4$ $\mathrm{pg} /$ testicule/h à $\mathrm{J} 1, \mathrm{~J} 2$ et $\mathrm{J} 3$ de culture respectivement, $n=9$ avec des testicules de 16,5 jpc). Enfin, l'immunorévélation de l'AMH a montré que l'expression de cette hormone augmente in vitro avec les testicules explantés à $13,5 \mathrm{jpc}$ (Figure $1 \mathrm{~A}$ et $\mathrm{B}$ ) et est maintenue in vitro avec les testicules plus âgés (données non montrées).

Jusqu'à 7 jours de culture, l'expression de l'AMH et l'organisation en cordons séminifères se sont révélées comparables dans le testicule cultivé et dans le testicule d'âge équivalent in vivo (Figure $1 \mathrm{C}$ ). Après 9 jours de culture d'un testicule de $14,5 \mathrm{jpc}$, les cordons ont tendance à se collapser (Figure $1 \mathrm{G}$ ) et, après 14 jours de culture presque tous les cordons sont altérés (Figure

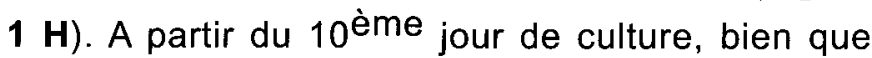
l'épithélium sertolien reste clairement structuré, les cellules péritubulaires aplaties ne sont plus identifiables (Figure $1 \mathrm{H}$ ).

\section{b) Souris}

In vivo, les cellules de Sertoli s'agrègent et entourent les gonocytes pour former les cordons séminifères entre 11,5 et $13,5 \mathrm{jpc}$. Nous avons observé que les cordons séminifères se différencient de façon comparable dans 
des testicules explantés à 11,5 jpc et cultivés dans notre dans notre système organotypique (Figure $1 \mathrm{D}$ et $\mathrm{E}$ ). La comparaison avec les stades équivalents in vivo n'a pas montré de différences majeures (Figure $1 \mathrm{~F}$ ).

En accord avec la littérature $[45,68]$, nous avons observé que le pourcentage de cellules de Sertoli incorporant le BrdU dans le testicule ex vivo augmente en fonction de l'âge jusqu'à un maximum à 17,5 jpc (Tableau 1) puis diminue ultérieurement (données non montrées). Comme chez le rat, les cellules de Sertoli maintiennent une forte activité mitotique après 3 jours de culture (Tableau 1).

Comme chez le rat, la sécrétion d'AMPc en réponse à la stimulation aigue par FSH augmente au cours de la culture, mais elle reste inférieure au niveau atteint in vivo au cours de la période correspondante (Tableau 1). L'expression de l'AMH augmente au cours de la culture pour les testicules de $11,5 \mathrm{jpc}$ et elle est maintenue pour les testicules plus âgés (donnée non montrée). Avec les jeunes testicules fœtaux (12,5 jpc) cultivés pendant plus de 5 jours, l'intégrité des cordons séminifères est préservée. Cependant, après une période de culture plus longue (10 jours) environ $80 \%$ des cordons montrent une morphologie perturbée (Figure $5 \mathrm{~J}$ ).

\section{c) Homme}

Pour chaque fœtus, nous avons fixé un testicule au moment de l'explantation (Figure $2 \mathrm{~A}$ et $\mathrm{C}$ ) et cultivé le testicule controlatéral pendant 4 jours en conditions basales. A la fin de la culture, l'architecture du testicule est bien préservée avec les cellules de Sertoli englobant les cellules germinales (Figure 2 B et D). L'expression de l'AMH est encore élevée dans les cellules de Sertoli. Nous n'avons observé aucun signe de nécrose ou de désorganisation tissulaire. Les cellules germinales montrent une morphologie caractéristique des gonocytes un cytoplasme claire limité par une membrane plasmique nette et un gros noyau sphérique contenant plus d'un nucléole (Figure 2 A-F).

\section{d) Conclusion}

Chez le rat, la souris et l'homme, durant les premiers jours de culture dans notre système organotypique, l'organisation, la prolifération et l'expression des fonctions différenciées des cellules de Sertoli se développent de façon similaire à celles observées in vivo bien que ces activités soient moins intenses qu'in vivo. Dans les cultures à long terme (plus de 10 jours) de rat et de souris, la morphologie des cordons séminifères est altérée.

\section{Comparaison du développement des gonocytes in vivo et in vitro}

\section{a) Rat}

Nous avions précédemment déterminé le nombre de gonocytes par testicule au cours du développement et montré que ce nombre augmente de 13,5 jpc jusqu'à $18,5 \mathrm{jpc}$, puis reste stable jusqu'à $3 \mathrm{jpp}$, stade où la prolifération redémarre [12, 39] (Figure 3). Dans notre système de culture organotypique, les changements du nombre de gonocytes dans les testicules explantés à différents âges et cultivés pendant quelques jours dans un milieu témoin sont comparables à ceux observés in vivo bien que le nombre total de gonocytes obtenus in vitro reste inférieur à celui observé in vivo (Figure 3).

Nous avions également précédemment déterminé le profil développemental des activités mitotiques des gonocytes en utilisant l'incorporation de BrdU ex vivo. Nous avions identifié deux périodes d'activité (l'une pendant le développement fœtal et l'autre pendant le développement néonatal) séparées par une période quiescente sans activité mitotique (Figure 4 A, [12]). Nous avons mesuré ici le pourcentage de gonocytes incorporant le BrdU pendant un pulse de $3 \mathrm{~h}$ après différents temps de culture de testicules explantés à 14,5 jpc (Figure 4 B et Figure 5 A-C). Nous avons observé que le pourcentage de gonocytes BrdU positifs diminue au cours des 5 premiers jours de culture à l'instar de l'évolution normale in vivo. Les gonocytes entrent ensuite dans une période de quiescence suivi d'une reprise spontanée des mitoses après 14 jours de culture ce qui correspond au stade néonatal de $6 \mathrm{jpp}$. Cependant, le nombre et le pourcentage de gonocytes reprenant leur mitose in vitro sont très inférieurs à ceux observés in vivo à 6 jpp.

Enfin, dans 6 cas sur 10, pour lesquels nous avons poursuivi la culture pendant 21 jours nous avons observé quelques rares cellules ressemblant à des spermatogonies A (Figure 5D). Comme nous l'avons signalé plus haut, au delà de 10 jours de culture, les cordons commencent à s'effondrer, et, après 21 jours de culture, la plupart d'entre eux sont désorganisés. Aussi, il est difficile d'assurer que ces cellules sont effectivement des spermatogonies sur la base de leur localisation dans les cordons comme pour les testicules de 10jpp (Figure 5 E) cependant elles ont le même aspect que les spermatogonies A observées in vivo à $10 \mathrm{jpp}$. Enfin il faut signaler que nous avons observé de très rares spermatocytes avec une condensation chromatinienne caractéristique du stade leptotène dans les testicules de 14,5 jpc cultivés pendant 21 jours (Figure 5 D insert). 

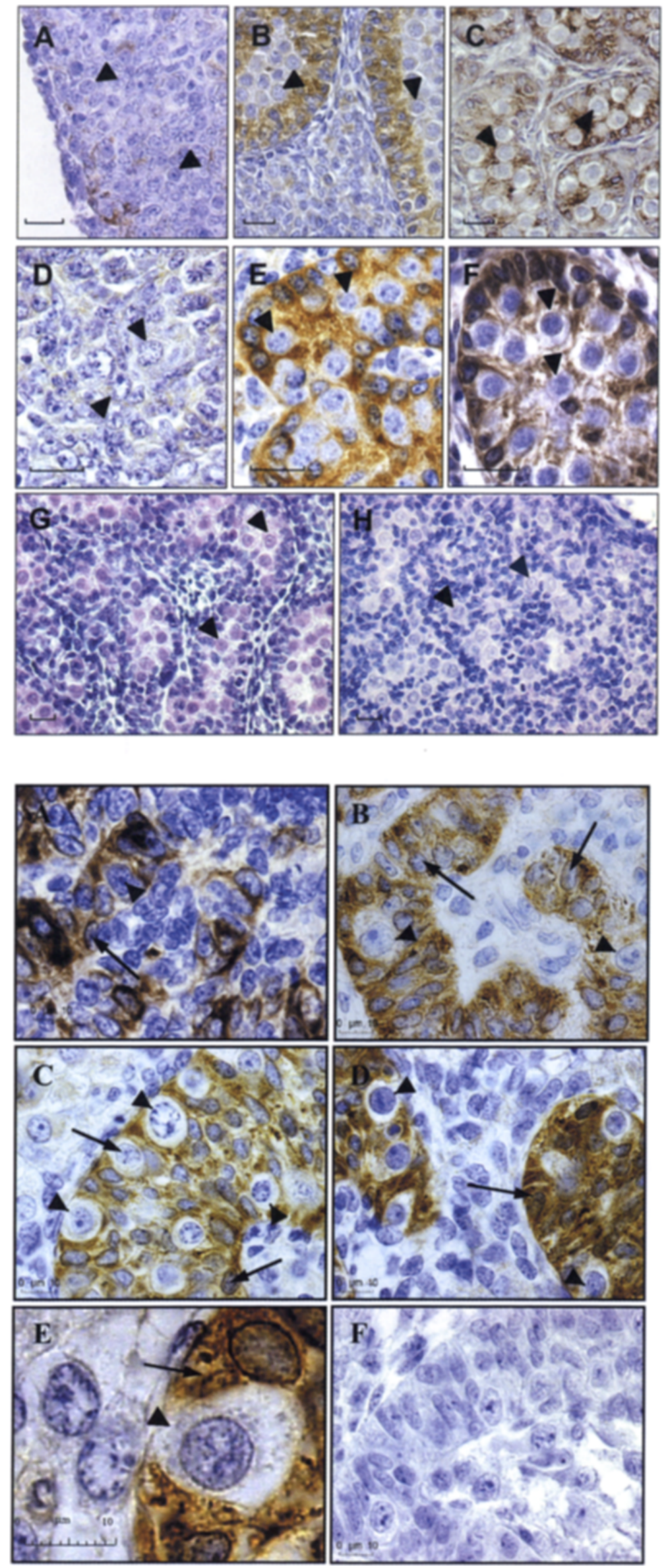

Figure 1 : Aspect histologique des testicules fœtaux de rat et de souris avant et après culture.

La révélation immunohistochimique de l'AMH a été réalisée avant $(A, D)$ et après $(B, E) 7$ jours de culture de testicules fotaux de rat de 13,5 jpc (A, $B$ ) et 4 jours de culture de testicules fotaux de souris de $11,5 \mathrm{jpc}(D, E)$. Les cultures ont été réalisées sur filtre qui flottent à la surface de DMEM/Ham F12 dépourvu de sérum, d'hormone et de tout autre facteur biologique. L'immunohistochimie de l'AMH a également été réalisée aux stades équivalents in vivo : $20,5 \mathrm{jpc}$ chez le rat (C) et 15,5 jpc chez la souris (F). Des coupes colorées à l'hématoxyline-éosine de testicules foetaux de rat de 14,5 jpc après 9 (G) et $14(H)$ jours de culture sont présentées. La barre d'échelle représente $20 \mu \mathrm{m}$. Les têtes de flèche désignent des gonocytes.

Figure 2 : Aspect histologique des testicules fœtaux humains avant et après culture.

Les testicules de 6 semaines $(A, B)$ ou plus âgés que 10 semaines $(C, D)$ ont été fixés dans le liquide de Bouin immédiatement après leur prélèvement $(A, C)$ ou après 4 jours de culture $(B, D, E)$ dans du DMEM/Ham F12 dépourvu de sérum, d'hormone et de tout autre facteur biologique. Les cellules de Sertoli (flèches) ont été identifiées par révélation immunohistologique de I'AMH ce qui permet d'identifier les gonocytes (pointes de flèches) non marqués au sein des cordons séminifères. Un témoin négatif de l'immunomarquage a été obtenu en remplaçant l'anticorps anti-AMH par du PBS (F). La barre d'échelle représente 10 $\mu m$. 


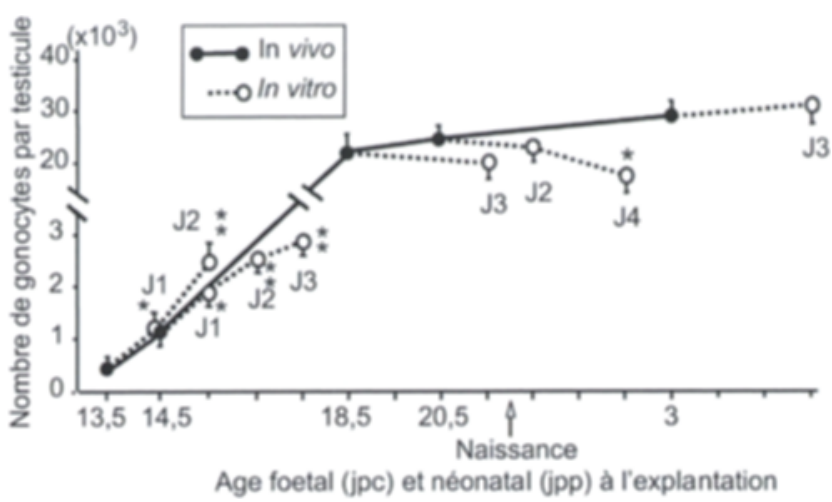

Figure 3 : Développement des gonocytes dans le testicule fœtal et néonatal de rat en culture. Les testicules fotaux ont été prélevés à différents stades fotaux (datés en jour post conception (jpc) ou néonataux (datés en jour post partum (jpp)) et cultivés sur des filtres flottants sur du milieu. Au moment de l'explantation (in vivo) et après 1 (J1), 2, (J2), 3 (J3) ou 4 (J4) jours de culture, les gonocytes contenus dans les testicules ont été comptés. Les valeurs sont la moyenne \pm SEM de 6 à 10 expériences. * : $P<0,05$ et ** : $P<0,01$ par rapport aux valeurs à l'explantation en utilisant le test " $t$ " de Student en valeurs appariées.

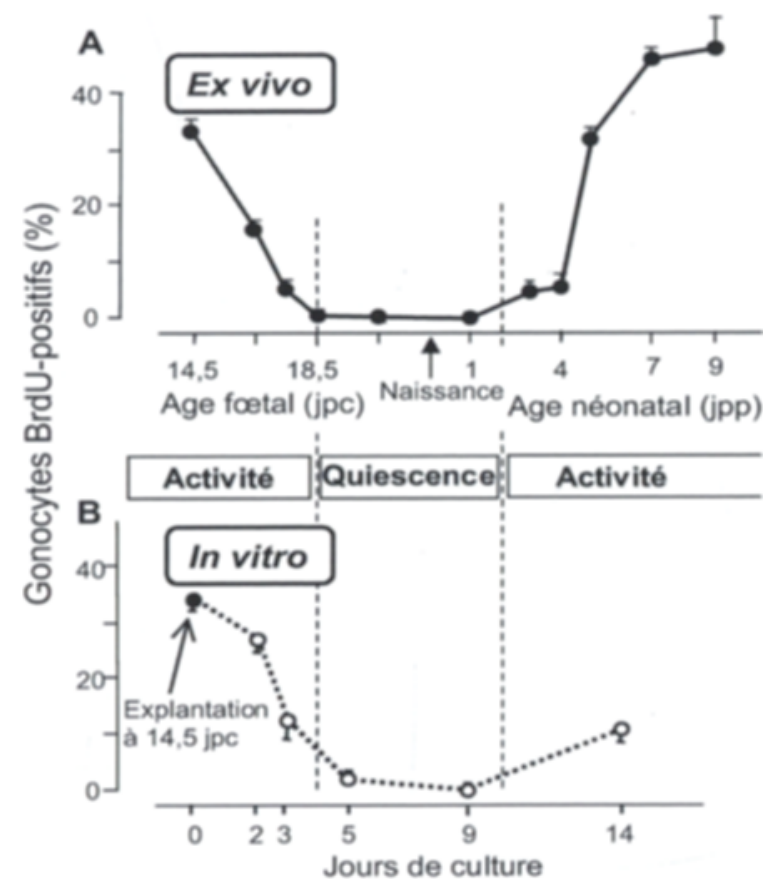

Figure 4 : Index d'incorporation du BrdU dans les gonocytes de testicules fotaux de rat ex vivo et in vitro. Les testicules fœetaux de rat ont été prélevés à différents jours post conception (jpc) et placés sur un filtre flottant sur du milieu comme décrit dans la légende de la Figure 1. Des testicules ont été cultivés pendant $3 \mathrm{~h}$ en présence de BrdU et le pourcentage de gonocytes BrdU positifs a été déterminé (graphe du haut : ex vivo). Les testicules de fœtus âgés de 14,5 jours ont été cultivés pendant 2, 3, 5, 9 ou 14 jours et le pourcentage de gonocytes incorporant le BrdU qui était ajouté pendant les trois dernières heures de culture a été déterminé (graphe du bas : in vitro). Les valeurs sont les moyennes \pm SEM de 4-5 expériences.
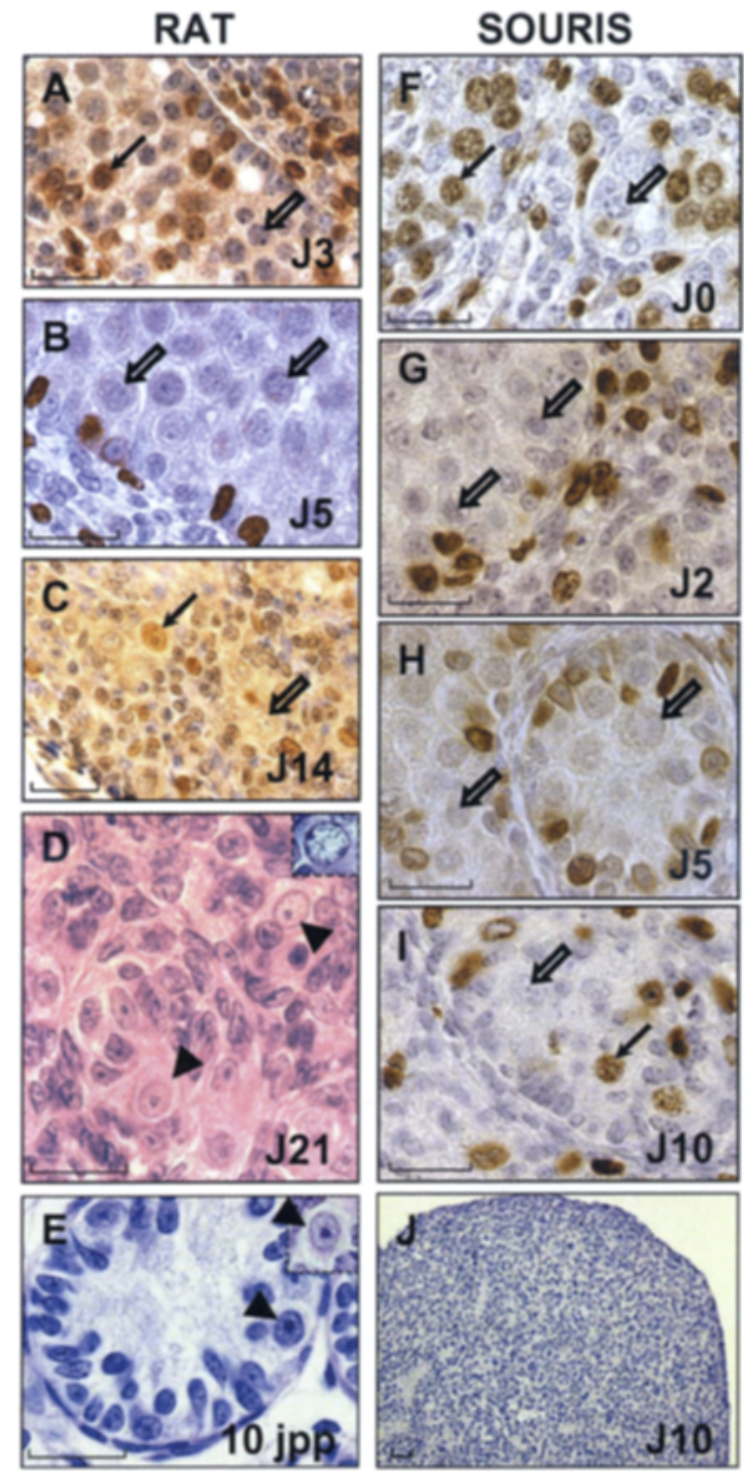

Figure 5 : Incorporation de BrdU dans les testicules de rat et de souris en culture. Les testicules ont été prélevés chez des foetus de rat de 14,5 jpc (A-D) ou de souris de 12,5 jpc (F-J) et cultivés sur des filtres flottants pendant 2 (G), 3 (A), 5 (B, H), 10 (I, J), 14 (C) ou 21 (D) jours et fixés dans le liquide de Bouin, coupés et colorés. En $A$ à $C$ et $F$ à $I$, le BrdU a été ajouté au milieu pendant les trois dernières heures de culture, et l'incorporation de BrdU dans le noyau a été révélée par coloration immunohistologique. Les flèches ouvertes désignent des gonocytes qui n'ont pas incorporé le BrdU et les flèches noires des gonocytes qui ont incorporé le BrdU. Les têtes de flèches indiquent des spermatogonies de type A observées après 21 jours de culture (D) et dans des testicules de rat de 10 jpp (E) avec une coloration à l'hématoxyline-éosine. La figure additionnelle dans l'insert $E$ montre une spermatogonie avec une coloration plus légère. L'insert $D$ montre un stade leptotène précoce observé après 21 jours de culture. J est une coupe observée au faible grossissement d'un testicule de fœtus de souris de 12,5 jpc après 10 jours de culture qui montre l'altération de la structure des cordons séminifères. Les barres d'échelle représentent $20 \mu \mathrm{m}$. 
Tableau 1 : Comparaison de la prolifération et de la différenciation des cellules de Sertoli in vivo et in vitro.

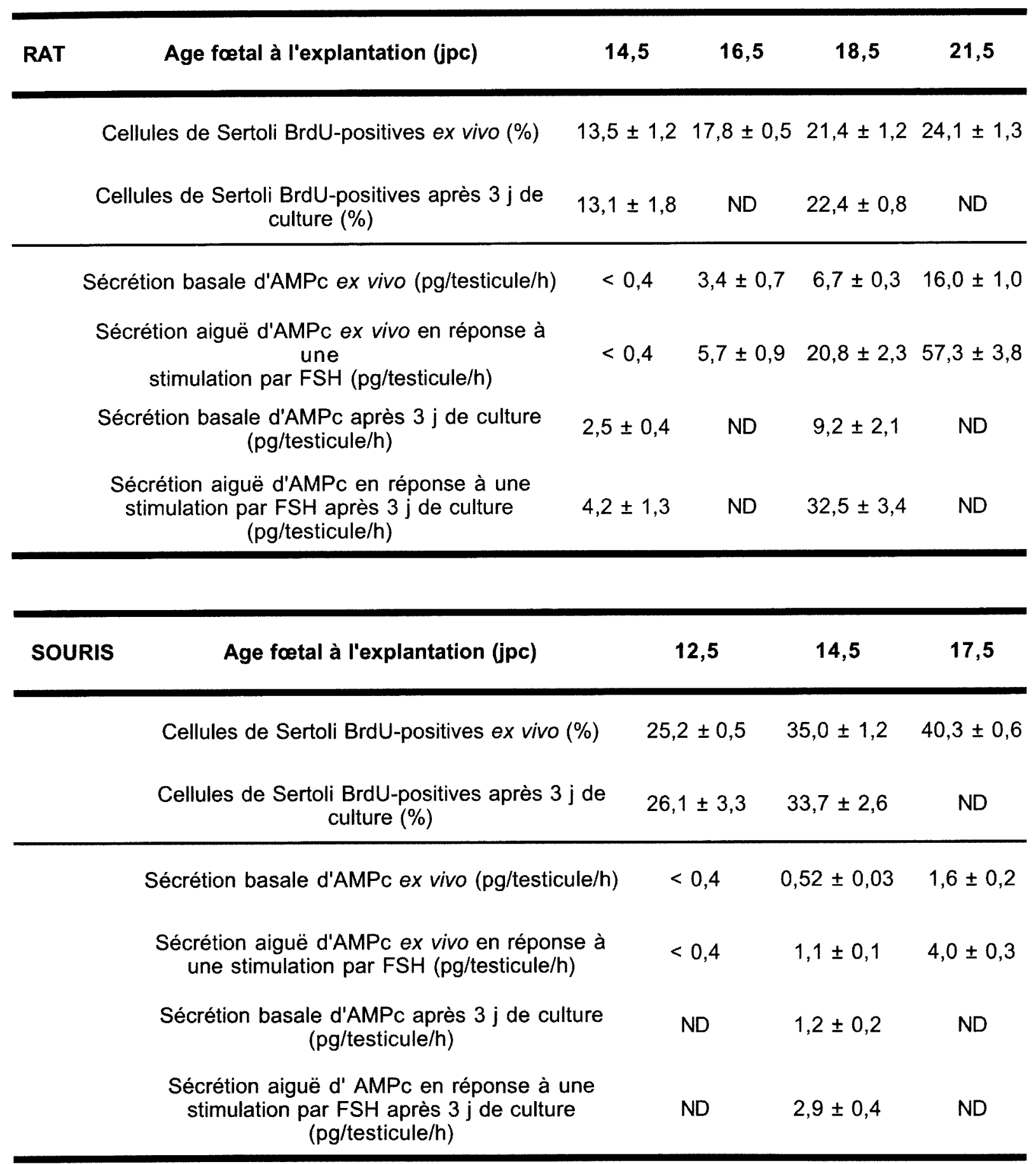

L'activité mitotique des cellules de Sertoli a été évaluée par l'incorporation de BrdU pendant 3 h. La différenciation des cellules de Sertoli a été évaluée par la mesure de l'AMPc produit en réponse à une stimulation aiguë par FSH. Les analyses ont été réalisées avec des testicules fœtaux de rat et de souris avant et après une culture de 3 jours sur un filtre flottant. Les valeurs sont les moyennes \pm SEM de 3 à 8 expériences. ND = non déterminé. 


\section{b) Souris}

Le nombre de gonocytes par testicule augmente in vivo jusqu'à un maximum à 14,5 jpc (Figure 6). Dans notre système de culture organotypique, le nombre de gonocytes augmente également dans les testicules explantés à $12,5 \mathrm{jpc}$, mais reste inférieur à la valeur de l'âge correspondant in vivo. Avec des testicules explantés à $13,5 \mathrm{jpc}$, le nombre de gonocytes reste constant au cours de la culture alors qu'il augmente considérablement au cours du développement in vivo. Avec des testicules explantés à 14,5 ou 15,5 jpc, le nombre reste stable au cours de la culture, à l'instar du développement in vivo (Figure 6).

Comme chez le rat, nous avons déterminé le pourcentage de gonocytes qui incorporent le BrdU au cours d'une incubation ex vivo de 3 heures. Le profil est similaire à celui du rat avec deux périodes d'activité mitotiques (l'une fœetale de 12,5 à 15,5 jc et l'autre néonatale à partir de $0 \mathrm{jpp}$ ) séparées par une période quiescente (Figure 7). Nous avons explanté les testicules à 12,5 jpc et mesuré le pourcentage de gonocytes incorporant le BrdU pendant un pulse de $3 \mathrm{~h}$ après différents temps de culture. Ce pourcentage diminue pendant les 2 premiers jours de culture à l'instar de l'évolution in vivo. Puis, les gonocytes entrent dans une phase de quiescence. Enfin, ils reprennent spontanément une activité mitotique entre 5 et 10 jours de culture ce qui correspond à la période pendant laquelle se produit la reprise des mitoses in vivo (Figure 7). La révélation immunohistochimique de l'incorporation de BrdU est illustrée Figure $5 \mathrm{~F}-\mathrm{I}$. II est intéressant de souligner que, bien que l'organisation en cordons séminifères du testicule soit fortement altérée après 10 jours de culture (Figure $5 \mathrm{~J}$ ), ceci n'empêche pas les gonocytes de reprendre leur mitose.

\section{c) Homme}

Nous avons évalué le nombre de cellules germinales par testicule ainsi que leur activité mitotique après 4 jours de culture et comparé ces valeurs avec celles obtenues au moment de l'explantation. Pour les testicules explantés avant 8 semaines, le nombre de cellules germinales reste le même au cours de la culture, alors qu'il diminue de 1,8 fois avec les testicules plus âgés (Figure 8 A). La prolifération, mesurée par la détection de Ki67, augmente au cours de la culture pour les testicules les plus âgés (Figure 8 B). L'activité apoptotique des cellules germinales mesurée par la révélation immunohistochimique de la caspase 3 clivée, tend à augmenter en culture à tous les âges, mais cette augmentation n'est significative qu'avec les stades les plus âgés (Figure $8 \mathrm{C}$ ).

\section{d) Conclusions}

Notre système in vitro permet de maintenir un profil de développement de la lignée germinale comparable à celui observé in vivo, bien que le nombre de cellules germinales obtenues in vitro soit très inférieur à la valeur correspondante in vivo. La gamétogenèse in vitro est plus facile à maintenir chez le rat que chez la souris et l'homme. Les cultures à long terme avec les testicules fœtaux humains sont en cours de réalisation dans notre laboratoire.

\section{Application de ce système de culture aux souris dont un gène vital a été invalidé}

L'analyse du rôle d'un gène dans le développement du testicule est impossible à conduire par la stratégie d'invalidation génique lorsque cette invalidation est létale. II est possible de contourner cet obstacle en explantant in vitro le testicule fœtal prélevé avant la mort de l'animal.

Ainsi, les souris homozygotes pour une inactivation de p63, une protéine de la famille p53, meurent à la naissance par déshydratation du fait de l'absence de formation de la peau en l'absence de p63 fonctionnel [44]. A 18,5 jpc, le nombre de gonocytes est légèrement supérieur chez les fœtus p63-/- en comparaison avec les fœtus sauvages mais la différence n'est pas significative. Pour analyser l'effet de l'inactivation de p63 sur les activités mitotiques et apoptotiques des gonocytes néonataux, nous avons prélevé les testicules chez les fœtus p63-/- et sauvages à 18,5 jpc (c'est-àdire 1 jour avant la naissance) et cultivé ces testicules pendant 3 jours. A la fin de la culture, le nombre de gonocytes est $38 \%$ plus élevé dans les testicules p63/- que chez les testicules sauvages (Figure 9 A). A la fin de la culture, $37 \%$ des gonocytes incorporent le BrdU ce qui indique que ces cellules ont repris normalement leur activité mitotique in vitro. Ce taux est inchangé après invalidation de p63 (Figure 9 D-F). En revanche, l'activité apoptotique des gonocytes, qui reprend également spontanément en culture, est réduite d'un facteur 3 après invalidation de p63 (Figure 9 GI). Ainsi, la complémentarité d'une approche in vivo (invalidation de p63) et in vitro (culture organotypique) nous a permis de mettre en évidence le rôle apoptotique fondamental de p63 dans l'apoptose naturelle postnatale des gonocytes.

\section{DISCUSSION}

Dans cet article, nous avons caractérisé un modèle de culture organotypique de la gamétogenèse foetale et néonatale en comparant le développement de la lignée germinale in vivo et in vitro dans trois espèces. Cette 


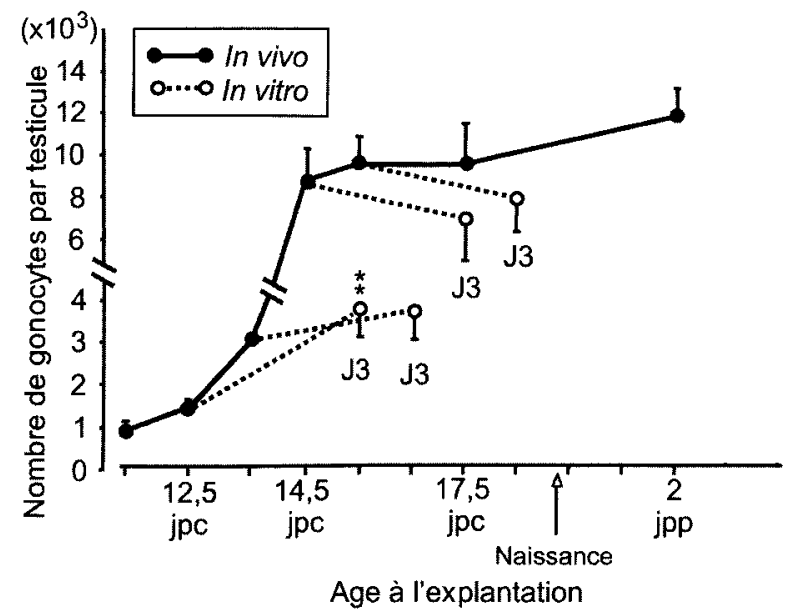

Figure 6 : Développement des gonocytes dans le testicule fœtal de souris en culture. Les testicules ont été prélevés à différents stades fœtaux datés en jours post conception (jpc) ou néonataux datés en jours post partum (jpp) et cultivés sur des filtres flottants sur du milieu synthétique. Au moment de l'explantation (in vivo) et après 3 jours de culture (J3), les gonocytes contenus dans le testicule ont été comptés. Les valeurs sont les moyennes \pm SEM de 4 à 5 expériences. ** : $P<0,01$ par rapport aux valeurs à l'explantation en utilisant le test " $t$ " de Student en valeurs appariées.

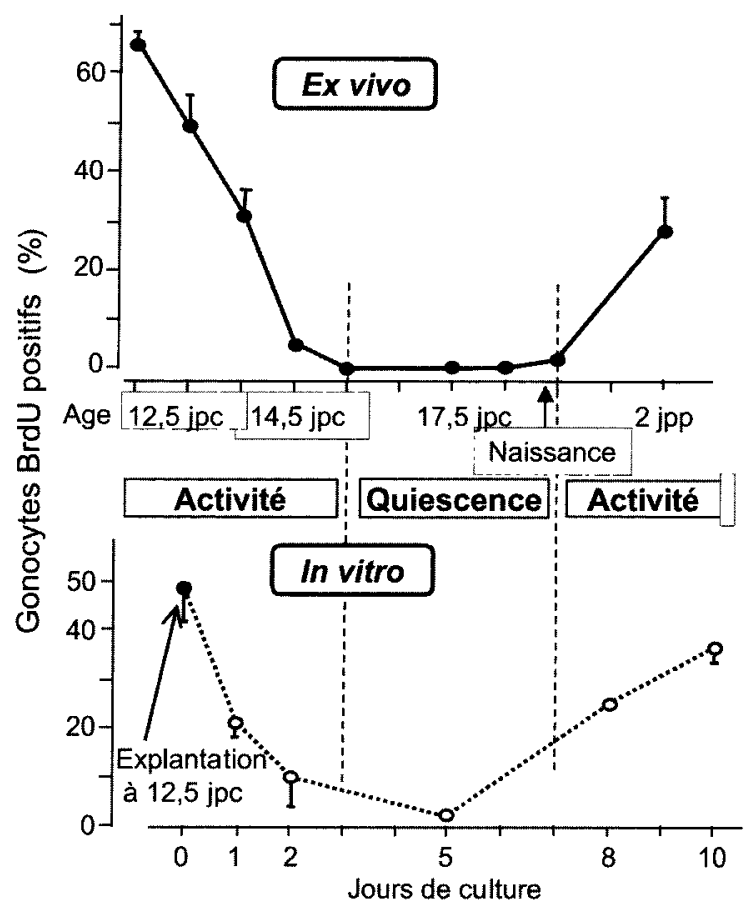

Figure 7 : Index d'incorporation du BrdU dans les gonocytes de testicules fœtaux et néonataux de souris ex vivo et in vitro. Les testicules de Souris ont été prélevés à différents jours post conception (jpc) ou post partum (jpp) et placés sur un filtre flottant sur du milieu comme décrit dans la légende de la Figure 1. Des testicules ont été cultivés pendant $3 \mathrm{~h}$ en présence de BrdU et le pourcentage de gonocytes BrdU positifs a été déterminé (graphe du haut : ex vivo). Les testicules de fœtus âgés de 12,5 jpc ont été cultivés pendant 1, 2, 5,8 ou 10 jours et le pourcentage de gonocytes incorporant le BrdU qui était ajouté pendant les trois dernières heures de culture a été déterminé (graphe du bas : in vitro). Les valeurs sont les moyennes \pm SEM de 4-5 expériences.
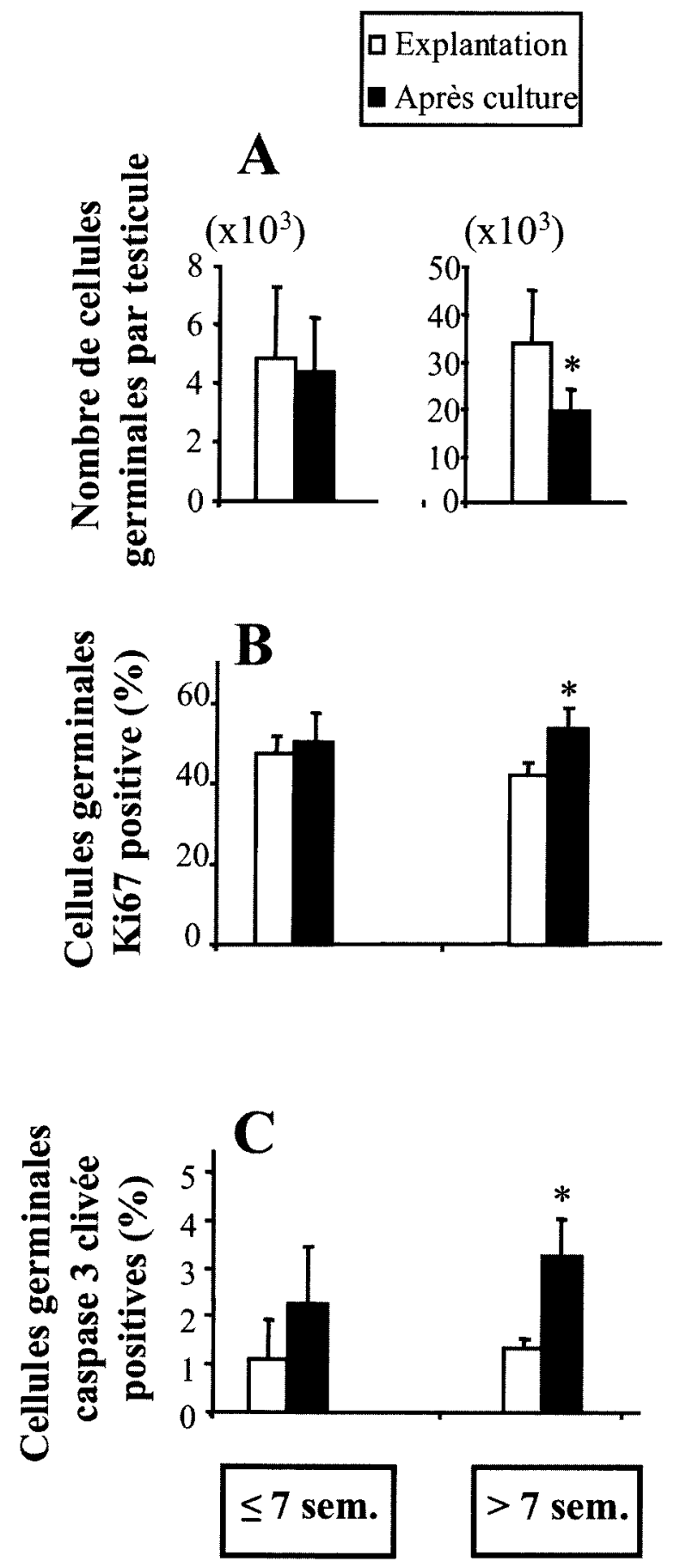

Figure 8 : Développement des gonocytes dans le testicule fœtal humain en culture. Les testicules ont été prélevés à 6 ou 7 semaines ou à 8-10 semaines. Un testicule a été immédiatement fixé dans le Bouin et l'autre testicule du même fotus a été cultivé pendant 4 jours sur un filtre flottant sur du milieu sans sérum ni hormone ou facteur de signalisation. Au moment de l'explantation (in vivo) et après 4 jours de culture, les gonocytes contenus dans les testicules ont été comptés (A), leur prolifération a été évaluée par la révélation de Ki67 (B) et leur activité apoptotique a été mesurée par la révélation immunohistochimique de la caspase 3 clivée (C). Les valeurs sont les moyennes \pm SEM de 3 à 6 expériences. * : P<0,05 par rapport aux valeurs in vivo en utilisant le test " $t$ " de Student en valeurs appariées. 


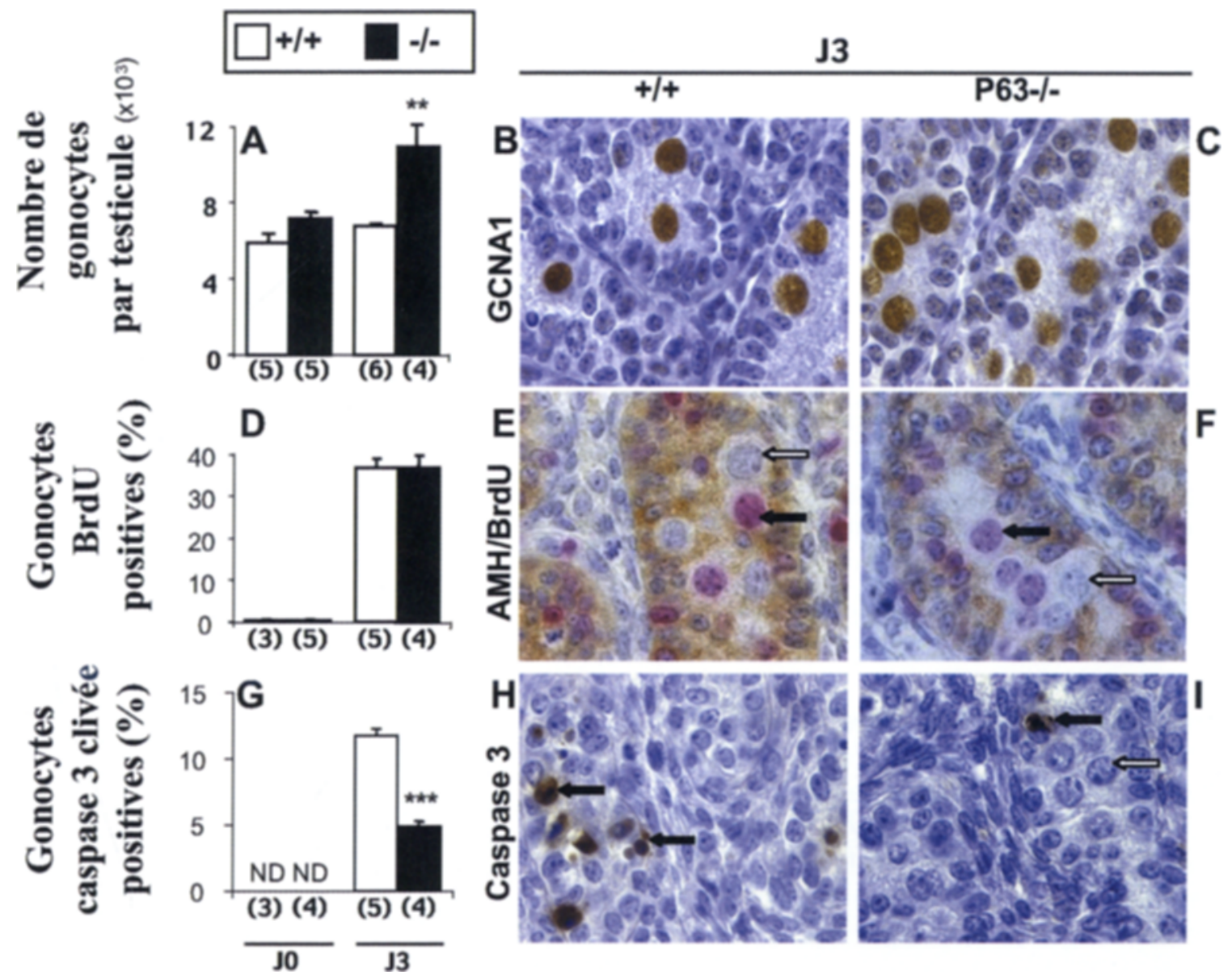

Figure 9 : Effet de l'invalidation de p63 sur le développement des cellules germinales. Les testicules P63+/+ (B, E, H) et P63-/ (C, F, I) de foetus à 18,5 jpc (J0) ont été cultivés pendant 3 jours (J3). Le nombre total de cellules germinales par testicule a été determiné après immunorévélation de GCNA1 (A, B, C). Le pourcentage de gonocytes ayant incorporé le $B r d U$ (noyau rouge) a été mesuré après marquage des cellules de Sertoli par révélation de l'AMH (marron) ( $D$, $E$, $F$ ). Le pourcentage de gonocytes contenant la caspase 3 clivée a été mesuré (G, $H$, I). Les colonnes représentent les moyennes \pm SEM d'un nombre $n$ d'expériences indiqué sous chaque colonne. ${ }^{* *} P<0,01$ and ${ }^{* * *} P<0,001$ dans le test de Student. ND, non détectable. La barre d'échelle représente $20 \mu \mathrm{m}$ et le même grossissement a été utilisé pour chaque image. Les gonocytes marqués pour le BrdU ou la caspase 3 clivée sont indiqués par des flèches blanches et les gonocytes non marqués par des flèches noires.

approche a permis d'établir la validité et les limites du modèle. Dans d'autres articles, nous avons démontré que ce modèle permet également de mimer le développement normal de la stéroïdogenèse testiculaire chez le rat à tous les stades et chez la souris et l'homme aux stades jeunes, mais qu'il est nécessaire d'ajouter de la LH chez la souris et l'homme aux stades âgés [17, $25,32,34,37,39,40,58]$.

Les fonctions des cellules de Sertoli (organisation en cordons séminifères, production d'AMH, production d'AMPc en réponse à la FSH) se développent ou se maintiennent correctement dans notre système in vitro pour les fœtus de tous les âges étudiés, mais l'organisation des cellules péritubulaires et des cellules de Sertoli en cordons séminifères est altérée après 10 jours de culture chez le rat et la souris.
Notre système permet le développement ou le maintien de la lignée germinale mais le nombre de gonocytes formés ou maintenus in vitro est très inférieur aux valeurs observées in vivo en particulier chez la souris à 13,5 jpc et chez l'homme. Chez l'homme, le nombre de gonocytes augmente au cours du premier semestre [8] alors que dans notre système de culture le nombre de gonocytes est seulement maintenu (fœtus de 7 semaines ou moins) ou même diminué (fœus de plus de 7 semaines). Malgré ces limites, notre système de culture est très performant. II est le premier qui rapporte une survie des gonocytes de rat et de souris pendant 10 ou 14 jours. En système de culture cellulaire, seulement $5 \%$ des gonocytes survivent après $24 \mathrm{~h}$ de culture [11].

Aussi bien chez le rat que chez la souris, les gonocytes 
reprennent leur mitose dans les testicules cultivés au même moment qu'in vivo après une période de quiescence correspondant à la période de quiescence observée in vivo. Ceci est une découverte importante car les cellules germinales sont des cellules difficiles à maintenir et faire évoluer in vitro. On peut noter qu'il est surprenant que les perturbations morphologiques de l'organisation testiculaire observée après de longues périodes de culture, n'empêchent pas les gonocytes de reprendre leurs mitoses et de se différencier en spermatogonies. Ainsi, ces étapes de la différenciation gonocytaire semblent pouvoir être réalisées indépendamment, au moins partiellement, d'une organisation très stricte au sein des cordons ce qui peut expliquer la capacité des gonocytes à donner des cellules germinales adultes lorsqu'ils sont transplantés dans les tubes séminifères d'une souris réceptrice [47].

Le maintien du développement des cellules de Sertoli et des gonocytes dans notre système in vitro confirme que ces processus sont largement indépendants des facteurs extratesticulaires $[28,48]$. Nos résultats soulignent également l'importance du maintien de l'architecture testiculaire et des relations intercellulaires pour optimiser le développement in vitro de la gamétogenèse. En effet les gonocytes isolés ont une survie très faible aussi bien en culture de gonocytes purifiés qu'en système dispersé $[11,67]$.

Nos analyses du développement des cellules de Sertoli et des gonocytes in vivo confirment les données bibliographiques pour le rat $[12,43,48,51]$ et la souris $[5,19,45,68]$. En outre, nous démontrons ici pour la première fois que l'activité (sécrétion basale) et le niveau de différenciation (sécrétion stimulée par FSH) de chaque cellule de Sertoli individuellement diminue avec l'âge fœtal chez le rat comme chez la souris. Chez le rat, nous avons rapporté ici qu'entre 16,5 et $21,5 \mathrm{jpc}$ la sécrétion d'AMPc en conditions basales ou stimulée par FSH augmente d'un facteur 5 à 10 alors que le nombre de cellules de Sertoli augmente d'un facteur 30 [43]. Chez la souris, entre 14,5 et 17,5 jpc la sécrétion d'AMPc en conditions basale ou stimulée par FSH augmente d'un facteur 3 à 4 alors que le nombre de cellules de Sertoli augmente probablement d'un facteur 6 sur la même période (valeur calculée à partir des données des références [5] et [45]): Nous avons décrit le même déclin pour les cellules de Leydig [37] et il reste à rechercher si son origine est la même que celui des cellules de Sertoli.

\section{CONCLUSION}

Cette étude montre que la gamétogenèse peut se développer in vitro avec une évolution comparable à celle observée in vivo en utilisant un système de culture organotypique dans lequel le testicule est placé sur un filtre qui flotte sur un milieu synthétique dépourvu de facteurs biologiques et de sérum. Cependant ce système est plus performant pour le rat que pour la souris et I'homme qui, à certains stades, montrent un faible maintien in vitro de la lignée germinale. Cette caractérisation du modèle est potentiellement très intéressante.

En effet, ce modèle peut être utilisé pour poursuivre le développement du testicule in vitro chez les souris porteuses d'une invalidation létale d'un gène comme illustré dans cet article avec le gène p63. Ce modèle permettra d'étudier l'effet sur la gamétogenèse de nombreux facteurs exogènes en fonction de l'âge du testicule, de la durée de l'exposition ou de la concentration du facteur. Ces facteurs peuvent être des hormones, des facteurs para/autocrines, des facteurs de signalisation, des perturbateurs endocriniens, des rayonnements ionisants. Ce modèle permet également d'étudier le rôle des facteurs intratesticulaires en utilisant des souris knock-out ou en ajoutant des siRNA au milieu.

Remerciements :

Romain Lambrot et Béatrice Petre-Lazar ont bénéficié d'un financement doctoral de l'Institut Scientifique et Technique Nucléaire du CEA. Nous remercions Aurélie Gouret pour son assistance secrétariale compétente et efficace, $C$. Joubert, $C$. Chauveau, $S$ Leblay et $V$. Neuville pour la qualité des soins qu'ils ont prodigués aux animaux et $F$. Guillou (INRA, Tours) pour les dosages de transferrine. Ce travail a été financé parl'Université Paris 7, le CEA et I'INSERM et par des contrats de l'Electricité de France (EDF), de Toxicologie Nucléaire Environnementale (CEA), et de l'Agence Française de Sécurité Sanitaire de l'Environnement et du Travail (AFSSET).

\section{REFERENCES}

1. ABERCOMBRIE M. : Estimation of nuclear population from microtome sections. Anat. Rec., 1946, 94 : 238-248.

2. ANDERSON R., GARCIA-CASTRO M., HEASMAN J., WYLIE C. : Early stages in males germ cell differentiation in the mouse. APMIS, 1998, $106: 127-133$.

3. ANWAY M.D., MEMON M.A., UZUMCU M., SKINNER M.K.: Transgenerational effect of the endocrine disruptor vinclozolin on male spermatogenesis. J. Androl., 2006. 
4. AUGER J., KUNSTMANN J.M., CZYGLIK F., JOUANNET $P$.: Decline in semen quality among fertile men in Paris during the past 20 years. N. Engl. J. Med., 1995, $332:$ 281-285.

5. BAKER P.J., O'SHAUGHNESSY P.J. : Role of gonadotrophins in regulating numbers of Leydig and Sertoli cells during fetal and postnatal development in mice. Reproduction, 2001, 122: $227-234$.

6. BEAUMONT H.M., MANDL A.M. : A quantitative study of primordial germ cells in the rat. J. Embryol. Exp. Morph., 1963, $11: 715-740$.

7. BEGEOT M., LANGLOIS D., PENHOAT A., SAEZ J.M. : Variations in guanine-binding proteins (Gs, Gi) in cultured bovine adrenal cells. Consequences on the effects of phorbol ester and angiotensin II on adrenocorticotropin-induced and cholera-toxin-induced cAMP production. Eur. J. Biochem., $1988,174: 317-321$

8. BENDSEN E., BYSKOV A.G., LAURSEN S.B., LARSEN H.P., ANDERSEN C.Y., WESTERGAARD L.G. : Number of germ cells and somatic cells in human fetal testes during the first weeks after sex differentiation. Hum. Reprod., 2003, 18: 13-18.

9. BENDSEN E., LAURSEN S., OLESEN C., WESTERGAARD L., ANDERSEN C., BYSKOV A. : Effect of 4-ocylphenol on germ cell number in cultured human fetal gonads. Hum. Reprod., 2001, $16: 336-343$.

10. BOITANI C., GIUDITTA POLITI M., MENNA T. : Spermatogonial cell proliferation in organ culture of immature rat testis. Biol. Reprod., 1993, 48 : 761-767.

11. BOULOGNE B., HABERT R., LEVACHER C. : Regulation of the proliferation of cocultured gonocytes and Sertoli cells by retinoids, triiodothyronine, and intracellular signaling factors: differences between fetal and neonatal cells. Mol. Reprod. Dev., 2003, $65: 194-203$.

12. BOULOGNE B., OLASO R., LEVACHER C., DURAND P., HABERT R. : Apoptosis and mitosis in gonocytes of the rat testis during foetal and neonatal development. Int. J. Androl., 1999, $22: 356-365$.

13. BUEHR M., GU S., MCLAREN A. : Mesonephric contribution to testis differentiation in the fetal mouse. Development, 1993 $117: 273-281$.

14. CUPP A., DUFOUR J., KIM G., SKINNER M., KIM K. : Action of retinoids on embryonic and early postnatal testis development. Endocrinology, 1999, 140 : 2343-2352.

15. DE SOUSA LOPES S.M., ROELEN B.A., MONTEIRO R.M. et al. : BMP signaling mediated by ALK2 in the visceral endoderm is necessary for the generation of primordial germ cells in the mouse embryo. Genes Dev., 2004, 18 : 1838-1849.

16. DELBES G., LEVACHER C., DUQUENNE C., HABERT R. : Is fetal testis in danger? Med. Sci., 2005, $21: 1083-1088$.

17. DELBES G., LEVACHER C., DUQUENNE C., RACINE C., PAKARINEN P., HABERT R. : Endogenous estrogens inhibit mouse fetal Leydig cell development via estrogen receptor alpha. Endocrinology, 2005, $146: 2454-2461$

18. DELBES G., LEVACHER C., HABERT R. : Estrogen effects on fetal and neonatal testicular development. Reproduction, 2006, in press.
19. DELBES G., LEVACHER C., PAIRAULT C. et al. : Estrogen receptor $\{$ beta\}-mediated inhibition of male germ cell line development in mice by endogenous estrogens during perinatal life. Endocrinology, 2004, 145 : 3395-3403.

20. ENDERS G.C., MAY J.J. 2ND. : Developmentally regulated expression of a mouse germ cell nuclear antigen examined from embryonic day 11 to adult in male and female mice. Dev. Biol., 1994, 163 : 331-340

21. EVTOUCHENKO L., STUDER L., SPENGER C., DREHER E., SEILER RW. : A mathematical model for the estimation of human embryonic and fetal age. Cell Transplant., 1996, 5: 453-464.

22. FUKUDA T., HEDINGER C., GROSCURTH P. : Ultrastructure of developing germ cells in the fetal human testis. Cell Tissue Res., 1975, $161: 55-70$.

23. GASKELL T.L., ESNAL A., ROBINSON L.L., ANDERSON R.A., SAUNDERS P.T. : Immunohistochemical profiling of germ cells within the human fetal testis : identification of three subpopulations. Biol. Reprod., 2004, 71 : 2012-2021.

24. GONDOS B. : Development and differentiation of the testis and male reproductive tract. In : Steinberger $A$., Steinberger E. eds. Testicular development, structure, and function. New York, Raven Press, 1980 : 3-20

25. HABERT R., DEVIF I., GANGNERAU M.N., LECERF L. : Ontogenesis of the in vitro response of rat testis to gonadotropin-releasing hormone. Mol. Cell. Endocrinol., 1991, 82 : 199-206.

26. HABERT R., LEJEUNE H., SAEZ J.M. : Origin, differentiation and regulation of fetal and adult Leydig cells. Mol. Cell. Endocrinol., 2001, $179: 47-74$.

27. HILSCHER B., HILSCHER W., BULTHOFF-OBNOLZ B. et al. : Kinetics of gametogenesis. I. Comparative histological and autoradiographic studies of oocytes and transitional prospermatogonia during oogenesis and prespermatogenesis. Cell Tissue Res., 1974, 154 : 443-470.

28. JOHNSTON H., BAKER P.J., ABEL M. et al. : Regulation of Sertoli cell number and activity by follicle-stimulating hormone and androgen during postnatal development in the mouse. Endocrinology, 2004, $145: 318-329$.

29. JOST A. : Données préliminaires sur les stades initiaux de la différenciation du testicule chez le rat. Arch. Anat. Micr. Morphol. Exp., 1972, 61 : 415-438.

30. JOST A. : Hormonal and genetic factors affecting the development of the male genital system. Andrologia, 1976, $8: 17-33$.

31. JOST A., MAGRE S. : Sexual differentiation. In : Thibault C., Levasseur M., Hunter R.H.F. eds. Reproduction in Mammals and Man. Paris, Ellipses, 1993 : 197-226.

32. LAMBROT R., COFFIGNY H., PAIRAULT C. et al. : Use of organ culture to study the human fetal testis development: effect of retinoic acid. J. Clin. Endocrinol. Metab., 2006, 91 : 2696-2703.

33. LE MAGueRESSE B., PINEAU C., GUILLOU F., JEGOU $B$.: Influence of germ cells upon transferrin secretion by rat Sertoli cells in vitro. J. Endocrinol., 1988, 118 : R13-R16. 
34. LECERF L., ROUILLER-FABRE V., LEVACHER C., GAUTIER C., SAEZ J., HABERT R. : Stimulatory effect of folliclestimulating hormone on basal and luteinizing hormonestimulated testosterone secretion by fetal rat testis in vitro. Endocrinology, 1993, 133 : 2313-2318.

35. LI H., KIM K.H. : Effects of mono-(2-ethylhexyl) phthalate on fetal and neonatal rat testis organ cultures. Biol. Reprod., 2003, 69 : 1964-1972.

36. LI H., PAPADAPOULOS V., VIDIC B., DYM M., CULTY M. : Regulation of rat testis gonocyte proliferation by plateletderived growth factor and estradiol: identification of signaling mechanisms involved. Endocrinology, 1997, 138 : 1289-1298.

37. LIVERA G., DELBES G., PAIRAULT C., ROUILLER-FABRE V., HABERT R. : Organotypic culture, a powerful model for studying rat and mouse fetal testis development. Cell Tissue Res., 2006, 324 : 507-521.

38. LIVERA G., PAIRAULT C., LAMBROT R. et al. : Retinoidsensitive steps in steroidogenesis in fetal and neonatal rat testes : in vitro and in vivo studies. Biol. Reprod., 2004, 70 : 1814-1821.

39. LIVERA G., ROUILLER-FABRE V., DURAND P., HABERT R.: Multiple effects of retinoids on the development of Sertoli, germ and Leydig cells of fetal and neonatal rat testis in culture. Biol. Reprod., 2000, 62 : 1303-1314.

40. LIVERA G., ROUILLER-FABRE V., HABERT R. : Retinoid receptors involved in the effects of retinoic acid on rat testis development. Biol. Reprod., 2001, 64 : 1307-1314.

41. MAGRE S., JOST A. : The initial phases of testicular organogenesis in the rat. An electron microscopy study. Arch. Anat. Micr. Morphol. Exp., 1980, 69 : 297-318.

42. MANNAERTS B., DELEEUV R., GEELEN J. et al. : Comparative in vitro and in vivo studies on biological characteristics of recombinant human Follicle-Stimulating Hormone. Endocrinology, 1991, 129 : 2623-2630.

43. MIGRENNE S., RACINE C., GUILLOU F., HABERT R. : Pituitary hormones inhibit the function and differentiation of fetal Sertoli cells. Endocrinology, 2003, 144 : 2617-2622.

44. MILLSA.A., ZHENG B., WANG X.J., VOGEL H., ROOP D.R., BRADLEY A. : p63 is a p53 homologue required for limb and epidermal morphogenesis. Nature, 1999, $398: 708-713$.

45. NAGANO R., TABATA S., NAKANISHI Y., OHSAKO S., KUROHMARU M., HAYASHI Y. : Reproliferation and relocation of mouse male germ cells (gonocytes) during prespermatogenesis. Anat. Rec., 2000, $258: 210-220$.

46. O'SHAUGHNESSY P., BAKER U., SOHNIUS U., HAAVISTO A.M., CHARLTON H., HUHTANIEMI I. : Fetal development of Leydig cell activity in the mouse is independent of pituitary gonadotroph function. Endocrinology, 1998, 139 : 1141-1146.

47. OHTA H., WAKAYAMA T., NISHIMUNE Y. : Commitment of fetal male germ cells to spermatogonial stem cells during mouse embryonic development. Biol. Reprod., 2004, 70 : 1286-1291.

48. OLASO R., HABERT R. : Genetic and cellular analysis of male germ cell development. J. Androl., 2000, $21: 497-511$.

49. OlASO R., PAIRAULT C., BOULOGNE B., DURAND P.,
HABERT R. : Transforming Growth Factor $\beta 1$ and $B 2$ reduce the number of gonocytes by increasing apoptosis. Endocrinology, 1998, $139: 733-740$.

50. OMEZZINE A., CHATER S., MAUDUIT C. et al. : Long-term apoptotic cell death process with increased expression and activation of caspase- 3 and -6 in adult rat germ cells exposed in utero to flutamide. Endocrinology, 2003, $144: 648-661$.

51. ORTH J.: The role of follicle-stimulating hormone in controlling Sertoli cell proliferation in testes of fetal rats. Endocrinology, 1984, $115: 1248-1255$.

52. ORTH J.M. : Proliferation of Sertoli cells in fetal and postnatal rats : a quantitative autoradiographic study. Anat. Rec., 1982, $203: 485-492$.

53. PAZ G.F., THLIVERIS J.A., WINTER J.S., REYES I.F., FAIMAN C. : Hormonal control of testosterone secretion by the fetal rat testis in organ culture. Biol. Reprod., 1980, 23 : 1087-1095.

54. PETRE-LAZAR B., LIVERA G., MORENO S.G. et al. : The role of p63 in germ cell apoptosis in the developing testis. $J$. Cell Physiol., 2006, in press.

55. POINTIS G., MAHOUDEAU J.A. : [Testosterone production by embryonic testis of mouse in organ culture]. C. R. Acad. Sci. Hebd. Seances Acad. Sci. D, 1974, 279 : 1197-1200.

56. ROBINSON L.L., TOWNSEND J., ANDERSON R.A. : The human fetal testis is a site of expression of neurotrophins and their receptors: regulation of the germ cell and peritubular cell population. J. Clin. Endocrinol. Metab., 2003, 88 : 39433951.

57. ROSS A.J., CAPEL B. : Signaling at the crossroads of gonad development. Trends Endocrinol. Metab., 2005, 16 : 19-25.

58. ROUILLER-FABRE V., LECERF L., GAUTIER C., SAEZ J.M., HABERT R. : Expression and effect of Insulin-like Growth Factor I on rat fetal Leydig cell function and differentiation. Endocrinology, 1998, 139 : 2926-2934.

59. SCHLATT S., ZHENGWEI Y., MEEHAN T., DE KRETSER D.M., LOVELAND K.L. : Application of morphometric techniques to postnatal rat testes in organ culture : insights into testis growth. Cell. Tissue Res., 1999, 298 : 335-343.

60. SCHLUTER C., DUCHROW M., WOHLENBERG C. et al. : The cell proliferation-associated antigen of antibody Ki-67 : a very large, ubiquitous nuclear protein with numerous repeated elements, representing a new kind of cell cyclemaintaining proteins. J. Cell. Biol., 1993, 123 : 513-522.

61. SHARPE R.M., IRVINE D.S. : How strong is the evidence of a link between environmental chemicals and adverse effects on human reproductive health ? Br. Med. J., 2004, 328 : 447 451.

62. SHARPE R.M., SKAKKEBAEK N.E. : Are oestrogens involved in falling sperm counts and disorders of the male reproductive tract ? Lancet, 1993, 341 : 1392-1395.

63. SKAKKEBAEK N.E., RAJPERT-DE MEYTS E., MAIN K.M.: Testicular dysgenesis syndrome : an increasingly common developmental disorder with environmental aspects. Hum. Reprod., 2001, 16 : 972-978.

64. STORGAARD L., BONDE J.P., OLSEN J. : Male reproductive 
disorders in humans and prenatal indicators of estrogen exposure. A review of published epidemiological studies. Reprod. Toxicol., 2006, 21 : 4-15.

65. TOPPARI J., LARSEN J., CHRISTIANSEN P. et al. : Male reproductive health and environmental xenoestrogens. Environ. Health Perspect., 1996, 104 : 741-803.

66. VAN DISSEL-EMILIANI F.M.F., DE BOER-BROUWER M., DE ROOIJ D.G. : Effect of Fibroblast Growth Factor-2 on Sertoli cells and gonocytes in coculture during the perinatal period. Endocrinology, 1996, 137 : 647-654.

67. VAN DISSEL-EMILIANI F.M.F., DE BOER-BROUWER M., SPEK E.R., VAN DER DONK J.A., DE ROOIJ D.G. : Survival and proliferation of rat gonocytes in vitro. Cell. Tissue Res., 1993, $273: 141-147$.

68. VERGOUWEN R.P., JACOBS S.G., HUISKAMP R., DAVIDS J.A., DE ROOIJ D.G. : Proliferative activity of gonocytes, Sertoli cells and interstitial cells during testicular development in mice. J. Reprod. Fertil., 1991, 93 : 233-243.

69. VIGIER B., TRAN D., DU MESNIL DU BUISSON F., HEYMAN Y., JOSSO N. : Use of monoclonal antibody techniques to study the ontogeny of bovine anti-Müllerian hormone. J. Reprod. Fert., 1983, $69:$ 207-214.

70. VOS J.G., DYBING E., GREIM H.A. et al. : Health effects of endocrine-disrupting chemicals on wildlife, with special reference to the European situation. Crit. Rev. Toxicol., 2000, $30: 71-133$.

71. WARTENBERG $H$. : Differentiation and development of the testes. New York, Raven Press, 1989.

72. WENIGER J.P. : Steroid secretion by foetal mammal gonads and its regulation by gonadotrophins. Reprod. Nutr. Dev., 1986, $26: 921-932$.

73. WOLFF E. : Sur la différenciation sexuelle des gonades de souris explantées in vitro. C. R. Hebd. Seances Acad. Sci., 1952, $234: 1712-1714$.

Communication présentée au XXIIème Congrès de la SALF, Marseille, 2005

Manuscrit reçu : septembre 2006 ; accepté octobre 2006.

\begin{abstract}
In vitro development of foetal male germ cells in rats, mice and humans
Gabriel LIVERA, Romain LAMBROT, René FRYDMAN, Hervé COFFIGNY, Catherine PAIRAULT, Béatrice PETRE-LAZAR, Stéphanie G. MORENO, Virginie ROUILLER-FABRE, René HABERT

The key role of the foetal germ cell line in the reproductive capacity of the adult has been known for a long time. More recently, the observed increase in male reproductive disorders such as the decline of sperm count and quality and the increased incidence of testicular cancer has been postulated to be due to alterations of foetal and neonatal testicular development in response to increasing environmental pollution. However, few tools are available to study foetal and neonatal germ cell line development and the effects of physiological or toxic substances on this process.

The authors have developed an organ culture system in which foetal or neonatal testis is grown on a filter floating on a synthetic medium free of serum, hormones or biological factors. This study, using rats and mice, first compared the long-term morphological and functional development of Sertoli and germ cells in this in vivo system. In rats, these cells developed normally over a period of two weeks in vitro. Fewer cells were produced than in vivo, but a similar level of differentiated function was observed. Germ cells, which are difficult to maintain in vitro, resumed mitosis after a quiescent period, at the same time as in vivo. Similar results were obtained with mouse fetuses, but this model was less efficient.

This culture model can be used to study post-natal development of the germ cell lineage in testes derived from foetuses on the last day of foetal life and invalidated for P63, that do not survive after birth. This gene was found to be involved in the regulation of germ apoptosis which resumes after birth in the mouse. Lastly, this model applied to the human species (from 6 to 12 weeks of gestation) showed that testicular architecture and germ cells can be maintained for 4 days with better efficiency at younger stages than at older stages.

In conclusion, testicular architecture and intercellular communications are sufficiently preserved to sustain gametogenesis in vitro with no added factors. This method is potentially useful to study the effects of various factors, particularly xenobiotics.

Key-Words: germ cells, foetus, culture, development, testis 